\title{
A Case Study - Hindrances and Success Factors in Student Projects
}

\author{
Marta Kristin Larusdottir \\ School of Computer Science, Reykjavik University, \\ Ofanleiti 2, 103 Reykjavik, Iceland \\ marta@ru.is
}

\begin{abstract}
Third year undergraduate students in Computer Science at Reykjavik University complete a practical project in which co-operation between the students and the industry is emphasized. The st udents form small groups and develop software for eighteen weeks at a company's site where they get access to all needed facilities. In this study the students were asked to state the hindrances they experienced. Data was gathered from eleven student groups both with interviews and on-line questionnaires three times during the project period. Furthermore a contact person at each company was interviewed one month after the delivery date and asked to rate the quality of the project work. Based on that rating the groups were divided in three categories, the best, the middle and the worst. The success factors characterizing the best groups were analysed. Also the custom ers were asked to rate what quality factors of the product they emphasized the most. The students did not experience many hindrances five weeks after the commencement of the project, but after nine weeks $73 \%$ of the groups named that understanding the requirements of the project was a hindrance. The methods of HumanComputer Interaction could be of great value for the students in these two periods, understanding the user, their tasks and the context of use. When only 4 weeks were left of the project the biggest hindrances for the groups were technical problems and lack of time. A study of the work of the best groups showed that the main success factors are: being very organized, keeping good co-operation in the group, and getting feedback from the customer and the users.
\end{abstract}




\section{Introduction}

The curriculum for the 3 year BSc degree study in Computer Science at Reykjavik University provides as solid theoretical foundation as well as putting emphasis on practical aspects that meet the needs of Icelandic industries, business and institutions. The number of students enrolled in undergraduate studies in Computer Science has been around 300 the last two years. It is compulsory for all students to work on a 12 ECTS final project. The students have two possibilities: A practical project in which co-operation between the students and the software industry is emphasized or a research based project where the students work with a researcher at the university. Most students choose the former alternative, which is described in this paper.

The companies invite a group of students to work on a software project suggested by a contact person at the company, here called the customer, and the students get all the needed facilities at the customer's site. It is valuable for the students to be able to experience how it is to work in the software industry while still in their studies and some of them have got recruited by the company after their graduation. Such a direct co-operation with the software industry is also positive for the university. The students are working in the industry on actual projects suggested by the customer, still the projects are controlled, all having the same duration and the students deliver similar effort each so the project are of similar size. These circumstances make it possible to study how it is for practitioners to work on their first software project out in the industry, what the main hindrances are that they experience during the software development and how the customers rate the outcome.

In this paper the progress of these practical student projects is studied from the students' perspectives. We want to explore what the success factors in students project work are, when in the project period the students experience hindrances, and what these hindrances are. To measure the success of the product, customers were asked to rate the students work one month after the delivery of the product. The customers were also asked about how they rate different quality attributes for the software product.

The remainder of this paper is organized as follows: In Section 2 related works are reviewed. Section 3 presents the experimental design and how data was collected. Section 4 presents the results while in Section 5 the findings are discussed.

\section{Related Work}

A software product is considered to be a success if it is delivered on time, within budget, and contains all specified features or services, as defined by the Standish group in their annual Chaos Report [1]. In 1994 the reported success rate was $16.2 \%$ for software projects, in 2004 it was up to $29 \%$ [2]. In these reports, the reasons for failure and success are studied. The major success factors in 1994 [1] were: 'user involvement', 'executive management support', 'clear statement of requirements', 'proper planning' and 'realistic expectations'. The failure factors were more or less 
the reverse of the success factors, that is: 'lack of user input', 'incomplete or changing requirements and specifications', 'lack of executive support' and 'technology incompetence'. In the Standish group study the focus was on the customer's view of what characterizes successful projects.

Other studies have reported on the software developer's view of successes in software projects. Linberg [3] found that developer's perceptions of success are very different from the traditional definition of a project success. The developers were asked to name their most successful project: 5 out of 8 participants named a project that was over budget by $419 \%$, over schedule by $193 \%$, and over size estimates by $130 \%$. The success factors they mentioned were: 'the product worked the way it was supposed to work', 'developing it was a technical challenge' and 'their team was small and high-performing'.

A recent study from Procaccino et. al. [4] reports on a survey of success factors that affect software developer's perception of project success and is based on several previous studies. The 29 success factors are divided into three groups, processrelated factors, work-related factors and project-related factors. The three highest rated process-related success factors were: 'requirements are clear and understood'; 'team is sufficiently skilled' and 'customer/user and team have good relationship'. The lowest two factors in that category were: 'The team was able to negotiate changes' and 'the team does not feel pressured'. There were 5 factors in the workrelated category, of which the highest two were: 'You had sense that you delivered sufficient quality' and 'You had sense of achievement' and the lowest was: 'You learned something new'. Of the nine project-related factors, the two highest factors were: 'requirements were met' and 'final system worked as intended', while the lowest factor was: 'the project was completed within budget'.

A recent study of Dannelly, et. al. [5] explored what factors students believe important to measuring the success of professional software development projects. The students were asked to assume they had graduated and were working for a company that was developing a software-based product. Because of their lack of industrial experience their opinion was based on academic training. The highest rated success factors from previous studies were gathered and the students' opinions of these were measured. Their findings generally correspond to the findings of Procaccino, et. al, [4]: the students find factors like: 'not feeling pressured', 'acquiring new skills' and 'being challenged' not important in contrary to the software developers. Both surveys showed that quality is important for students and developers as well as factors like: 'The product meets customer's needs' and 'the customer finds the product useful and easy to use'. The major difference in opinions was that the students rated the factor 'within budget' as very important were as the developers rated it rather low.

In a study from Verner, et. al. [6] Australian software practitioners were surveyed to understand what software development practices were used in their recent software projects. The authors were particularly interested to discover what project management practices are common in Australian software projects and why some projects succeed and others fail. Their results show that the success factors are: 'Skilled project manager', 'good and complete requirements', 'good schedule and estimates' and 'working long hours'. 
Finally, Berntsson-Svensson, et. al. [7] give a good summary, based on eight papers, of the results of studying both project and product success factors in software projects. Based on this summary a questionnaire was made to investigate software project and product success factors in Swedish and Australian software companies. The study compared the similarities of success factors across three categories of industries: financial services, consulting industry and telecommunication industry. There are two factors that all three industry types considered as important for project success: 'complete and accurate requirements from project start' and 'having enough time for requirements elicitation'. All subjects considered 'a satisfied customer' as being the most important factor for product success.

In the context above, it can be concluded that students working on a practical project are good representatives for software developers, because they rate the success factors similar to developers [5]. Many of these studies state the success factors and failure factors in project work from the developer's perspective. In all of the above studies data is gathered after the project is delivered. In our study, however, we follow the progress of the students work, and see how the hindrances change during the software development process, to be able to understand better the success and failure factors. Also we want to measure the customer's perceived success of the work after the delivery of the product and analyze the success factors in the project work according to that rating. It can also be concluded that there are many different success factors stated in the literature, but many of the studies state that a satisfied customer is very important for product success. In our study we want to look deeper into that issue and describe what makes a customer satisfied by analysing what quality attributes our customers emphasize.

\section{Materials and Methods}

In this section we describe the subjects and the process and of the student projects, the purpose of the study, and the data gathering methods used.

\subsection{The Subjects of the Student Projects}

The subjects of the practical projects can vary a lot, two examples are: A system to register attendance during athletic lessons by GSM-phone and a web for the parents to check their kids attendance; and a system to seet passengers in a airplane to distribute the weight evenly. The students work on 'a new idea', they gather and analyze requirements, design, implement and test the software. Documentation during the whole project is emphasized. Often the projects are a part of a larger system, adding some new functionality to an existing system, for example adding a home accounting functionality to an internet bank. Most often there are actual endusers that work with the delivered systems so the students have to place emphasis on usability, although occasionally the students are making system functions with no user interface. In some cases the projects are a 'proof-of-concept', the students have to find a way to solve technical things, and occasionally the companies define the 
projects as prototypes to see how tasks can be solved in an easy way in the new software.

\subsection{The Process of the Student Projects}

The students work in groups of 2 to 4 persons. Usually each student contributes around 400 hours during the project, so the size of the projects is $800-1600$ manhours. All the groups follow the same process, which is as follows:

1. Contact persons from Icelandic companies send in suggestions for student projects to the final projects organizer. Usually these companies are developing software and the suggestions are for software projects that would fit into their development.

2. All incoming suggestions are made accessible to students at the same time.

3. The students form groups and ask the company they want to work with, if the project is available. When the students have got an agreement from a company for a particular project, they deliver a more detailed project description to the final project organizer.

4. An organizing committee having three members reads through the project descriptions and checks if the projects are suitable as a final project in Computer Science.

5. When the projects have been accepted, one supervisor and one censor are assigned for each group.

6. All the final projects start on the same date and are delivered on the same date, eighteen weeks later.

7. There are three checks in the project period where the students inform the supervisor, the censor and the final projects organizer on the status of the project. These check points are 4 weeks after the project started, 8 weeks after and near the end of it. The group meets the supervisor weekly. For this study there were additionally three check points were the groups were interviewed: five weeks, nine weeks and fourteen weeks after the commencement of the projects.

8. The students deliver a running system and supplying documentation at the end of the project period. After the final delivery, the students give a formal 30 minutes presentation of their projects, which is open to public.

\subsection{The Purpose of the Study}

The purpose of this study is to answer the following questions:

1. What are the main hindrances that the students experience during the practical project work and do they change during the project period?

2. What feedback channels do the students value the most during the project period?

3. How does the customer rate the groups work?

4. What quality attributes of the product does the customer emphasize?

5. What are the success factors to get high rating from the customer? 


\subsection{The Data Gathering}

We gathered data by two on-line questionnaires followed by structured interviews with each student, three times during the project period. Additionally structured interviews were conducted with the customer one month after the delivery date. Eleven student groups took part in the study, 45 students in total.

\subsubsection{The On-line Questionnaires for the Students}

We gathered data through two on-line questionnaires one for background information of the students and another for measuring the progress of the projects. The latter was sent out two times during the project period. There were 17 questions in the background questionnaire covering background information, the student's relation with other group members, and their concerns about the project. There were 38 questions in the process questionnaire covering the students experience in the requirements analysis phase, design phase, and implementation phase.

\subsubsection{The Interviews with each Student}

Interviews were conducted three times, 135 interviews in total. The interviews were conducted five weeks, nine weeks and fourteen weeks after the project start. The total project duration was eighteen weeks.

At each interview there was a conductor of the interview and a note-taker. There were 20 questions covered in the first structured interview, covering the process of the project, the hindrances that the students had experienced so far, and general questions about the group work. All the interviews were audio recorded. In the second and the third interview there were 28 questions, going in more detail into the progress of the projects than in the first interview.

\subsubsection{The Interviews with the Customers}

We conducted 11 structured interviews with the customers. At each interview there was a conductor of the interview and a note-taker. All the interviews were audio recorded. The questionnaire covered 49 questions in total, there were 9 questions about their rating of the students work and 40 questions on the six quality attributes from ISO-9126 [8], usability, functionality, reliability, efficiency, maintainability and portability.

\section{Results}

In here we present our results about the main hindrances found by the students and the customers rating of the students work. This is followed by a discussion of the common factors in the student group work and finally results are presented about what quality attributes the customers emphasise. 


\subsection{The Main Hindrances in the Project Work}

In the interviews, the students were asked about the main hindrances they had experienced in the period following the last interview. There were three periods, the first five weeks of the project, the next four weeks, and the next five weeks.

\subsubsection{The $1^{\text {st }}$ Period}

The main hindrances that the students mentioned in the first period of the project work can be seen in Table 1 .

Table 1. The main hindrances in the 1st period of the students project work

\begin{tabular}{|l|l|}
\hline Hindrance & \% of groups \\
\hline Lack of experience in project planning & $27 \%$ \\
\hline Lack of time & $27 \%$ \\
\hline Unclear or changed requirements & $18 \%$ \\
\hline Unclear project description & $18 \%$ \\
\hline
\end{tabular}

The groups named only one or two hindrances at this point and two groups did not name any. At this time the groups are starting the project work, so it is not surprising that the project plan and gathering requirements is hard for them. What is surprising is how few groups mention this.

\subsubsection{The $2^{\text {nd }}$ Period}

The hindrances the groups named in the second period can be seen in Table 2 .

Table 2. The main hindrances in the $2^{\text {nd }}$ period of the students project work

\begin{tabular}{|l|l|}
\hline Hindrance & \% of groups \\
\hline Understanding the project & $73 \%$ \\
\hline Technical problems & $55 \%$ \\
\hline Designing and implementing the database & $45 \%$ \\
\hline Lack of time & $36 \%$ \\
\hline Unclear or changed requirements & $36 \%$ \\
\hline Problems in the implementation & $36 \%$ \\
\hline Hard to describe use cases and user roles & $36 \%$ \\
\hline
\end{tabular}

Many of the groups mentioned that fully understanding the project is a hindrance. Here they have been working on the project for nine weeks and realize now what they do not know. Also they are having all sorts of technical problems, with the development environment they are working in. 


\subsubsection{The $3^{\text {rd }}$ Period}

The main hindrances from the third period can be seen in Table 3 .

Table 3. The main hindrances in the $3^{\text {rd }}$ period of the students project work

\begin{tabular}{|l|l|}
\hline Hindrance & \% of groups \\
\hline Technical problems & $75 \%$ \\
\hline Lack of time & $75 \%$ \\
\hline Designing and implementing the database & $63 \%$ \\
\hline Problems in the implementation & $50 \%$ \\
\hline Problems because of legacy systems & $38 \%$ \\
\hline Lack of knowledge of the version control system & $38 \%$ \\
\hline
\end{tabular}

The students have been working on the project for fourteen weeks and have four weeks left. Here many of the groups name that they have technical problems and are lacking time to achieve what they wanted. The students are still having trouble while designing and implementing the database.

\subsubsection{The Lessons Learnt}

As a Human-Computer Interaction (HCI) educator I see opportunities in helping the students in the $1^{\text {st }}$ period while gathering requirements. This can be done by emphasizing the methods described in the HCI literature for gathering information from the users and describe the users side of the software, for example contextual interviews, scenarios and personas. It is utterly important in this period to look at the context in which the users are working.

In the $2^{\text {nd }}$ period the main hindrance was to understand the project and there the methods for understanding the user and the task will be of a great help to the students. Encouraging the students to interview the users, look at the context, analyze the users and tasks, make paper prototypes, and get feedback from the users early in the development period would for sure help the students to understand the project domain better.

In the $3^{\text {rd }}$ phase the most frequent hindrances were technical problems and lack of time. There are not any particular HCI methods that could help to cope with these hindrances.

\subsection{The Customers Rating of the Groups}

The customers were asked to rate the students work on the scale from one to five where five is the best. The rating was supposed to reflect on both the delivered system and how professionally the group worked during the development process. The results from the customer ratings are shown in Table 4. 
Table 4. The customers rating of the groups work and delivery

\begin{tabular}{|l|l|l|l|l|l|}
\hline Customer rating & 1 & 2 & 3 & 4 & 5 \\
\hline Number of groups & 0 & 0 & 4 & 4 & 3 \\
\hline
\end{tabular}

As can be seen in Table 4, three projects got the highest rating from the customer, four projects ranked as the middle ones and four ranked as worst. The projects will be labelled according to this grouping in the following as the worst, the middle and the best. When asked about the reason for the best ratings the customers stated that the groups were very organized, always delivered in the documentation as planned and delivered in a system that was put into use. For the worst groups, the customers commented that the groups did not follow the predefined requirements, did not contact the customers much and worked very isolated and unorganized.

\subsection{The Highest Rated Feedback Channels}

The students were also asked which feedback they valued the most. They were asked to name one feedback channel. The results are shown in Table 5 grouped by the customers rating of the students work.

Table 5. Feedback channels that the students value the most

\begin{tabular}{|l|l|l|l|}
\hline & \multicolumn{3}{|l|}{ Student projects } \\
\hline Feedback during the project work & Worst & Middle & Best \\
\hline Customer & $68 \%$ & $48 \%$ & $33 \%$ \\
\hline User & $0 \%$ & $10 \%$ & $22 \%$ \\
\hline Supervisor & $26 \%$ & $39 \%$ & $39 \%$ \\
\hline Examiner & $5 \%$ & $3 \%$ & $6 \%$ \\
\hline
\end{tabular}

These results are interesting, especially for HCI educators because the students doing the best projects name in $22 \%$ of the cases that the best feedback comes from the users, but no students doing the worst projects mentions this. So someone in the group taking care of getting feedback from the user could be one success factor in doing to do good projects.

What is also of interest here is that the groups doing the worst project say in $68 \%$ of the cases that feedback from the customer is the most important feedback channel. When looking closer at the comments from the customers on the worst groups we see that the customers complain that the students in these groups worked in isolation and did not ask the customer questions or for advices. The customers thought that the delivered system was very different from the system they had asked for and commented that if the students had been more in touch they would have done a better system. The students were probably to shy to ask for the customers comments. 


\subsection{The Success Factors in the Project Work}

When looking into more detail at the data that was gathered in the interviews with the students some factors were common for the groups sharing the same rating from the customer. The success factors are drawn from analyzing the common factors from the groups.

\subsubsection{Common Factors - the Worst Projects}

The groups doing the worst projects had in common that the project management was lacking. They did not have any project plan for the whole project period, but made project plan week by week, day by day, or even did not plan at all. As a result they did not really know when the other group members would be working on the project. There was nobody taking the role of a project manager, no one kept track of things and encouraged the group members to stay focused. The groups did not work steadily during the project period, but worked in some working sessions.

The lack of facilities is one negative factor for the worst projects. The customers did not have the facilities for the students they had promised, for the entire duration of the project. This could indicate that getting a common room for the group during the whole project period preferably at the customer's site, is very important for the project's success.

\subsubsection{Common Factors - the Middle Projects}

The groups doing the middle ranked projects had in common that they were only missing minor things to get the highest rating. All the customers were quite satisfied with the delivered system.

The groups were somewhat organized, but they did not follow their project plan in detail. There was divided responsibility, for example someone was responsible for the documentation and another one for the programming. There was not enough communication in the group, so the person responsible for the documentation was not sure on the progress in the programming and visa versa. The groups did not have a detailed work schedule so the group members where on site when it suited them.

\subsubsection{Common Factors - the Best Projects}

The groups doing the best projects were very well organized. They did a project plan right in the beginning and referred to that plan during the whole project period. There was very good co-operation in the groups and these groups made a schedule for each week so all the group members would be in same place at the same time for several hours a week. The groups were very focused, so the time they were together was only used to work on the final projects. All the groups had one project manager that kept track of time spent on each task and was responsible for communicating with the customer and the supervisor.

All the groups had good co-operation with the customers and some co-operation with the users of the systems.

\subsubsection{The Success Factors}

To sum up the success factors we read from these results, the issues that are vital for the students to be able to do good projects, are listed here below: 
- Assign the role of a project manager to one member of the group

- Have an agreed working schedule for each week so the group meets at the same time on the same place several times per week

- Register the hours spent on each task carefully and compare that to the project plan each week

- Be focused when working on the project

- Keep good co-operation in the group

- Have a shared working room for the whole group the whole project period, preferably at the customers site

- Take the initiative to ask the customer for advice

- Assign one person in the group responsible for getting feedback from users

- Put emphasis on the requirement phase to discover the essence and hindrances in the project work early in the project period.

So the recommendations we have for the students beginning their final projects are to emphasise these success factors. We tell them to be organized: assign a project manager, do a project plan and keep track of the progress of the work, decide when and how many hours a week they are going to work on the projects. We also tell them to take good care of the communication within the group, with the customer and the users. Finally we advice them to take good time for requirements gathering and use the methods thought on that.

\subsection{Results on Quality Attributes}

The customers were asked to rate the six quality attributes from ISO 9126 [8]: usability, functionality, reliability, efficiency, maintainability and portability on a scale 1 to 5 , where 5 is the best, and point out which of the factors they regard as the most important one. Some customers could not name only one so they mentioned two. The results are shown in Table 7.

Table 7. The most emphasized quality factors

\begin{tabular}{|l|l|}
\hline Quality factor & Number of customers \\
\hline Functionality & 3 \\
\hline Usability & 2 \\
\hline Usability and Functionality & 3 \\
\hline Usability and Reliability & 1 \\
\hline Maintainability & 1 \\
\hline Maintainability and Portability & 1 \\
\hline Efficiency & 0 \\
\hline Total & 11 \\
\hline
\end{tabular}


So there were 6 customers that mentioned that functionality was the most important or one of the most important quality factors, and there were also 6 customers that mentioned usability as the most important attribute or one of the most important attributes. Two customers mentioned maintainability, one customer mentioned reliability and one portability. Nobody mentioned efficiency as the most important quality factor. In Fig. 1, the rating for usability and functionality is shown.

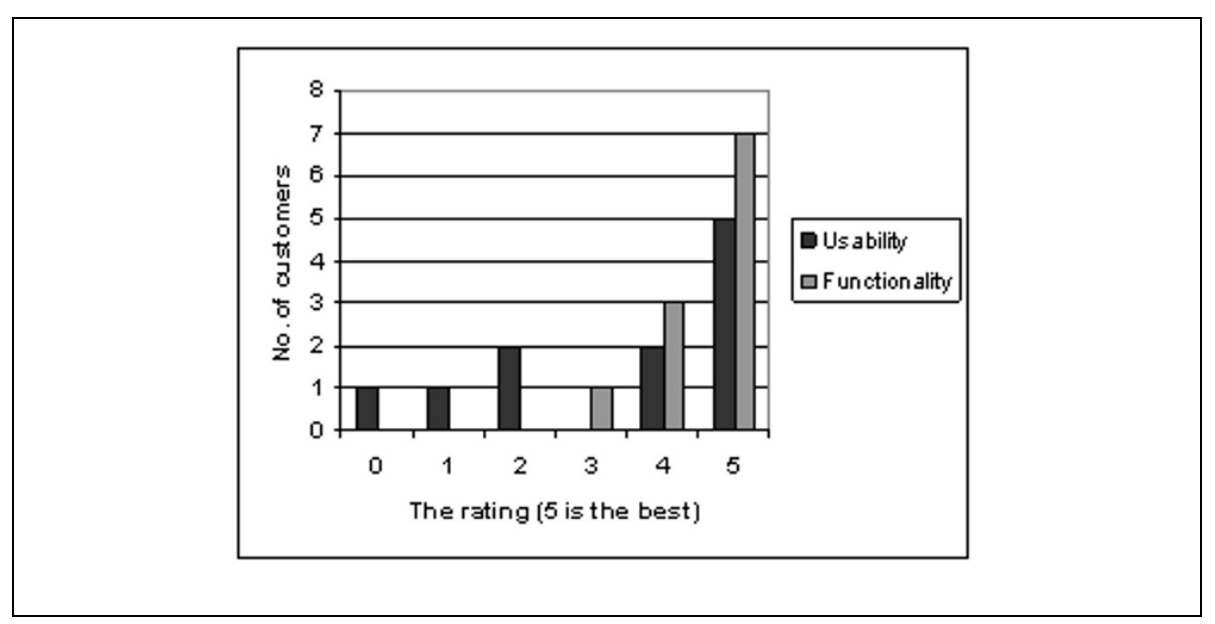

Fig. 1. The customer's ratings of the importance of the quality attributes

All the customers rated functionality as three or above and 7 customers gave it the highest rating. For usability the score is more mixed, seven customers say that it is very important and four give it a very low score, so there is a different pattern there, it is either very important or not important at all, while functionality is always regarded as somewhat important.

\section{Discussion}

The results of this study were interesting in many ways. Firstly, the students did not mention many hindrances in the project after the first four weeks. We would have imagined that at that point they would be very frustrated with not having a clear picture of the requirements of the project. However, they named a lot more hindrances later in the project. The most interesting result is that $73 \%$ of the students mentioned that they did not have a clear understanding of the requirements of the project when half of the project period had passed. It seems like the students discover how many unclear things there are when digging in the project, but do not really see all of these right in the start.

During their education it has been stressed that success factors like the ones from the Standish report from 1994 [1], for example 'clear statement of requirements', are very important. Also, developers from the Procaccino, et. al study [4], give the 
success factor 'requirements are clear and understood' the highest rating. In that study the developers give their rating after the project is delivered, so they know by then that this is very important. From our study we can see that the developers are already half way through the project when they discover this and would most likely benefit from emphasizing this earlier in the project. This gives HCI educators the indication that students would benefit of using the data gathering methods from the HCI literature to be able to understand the projects better right from the start.

Another interesting result of the study is that the students who received the poorest rating from the customer, thought in $68 \%$ of the cases that feedback from the customer was the most valuable one. On the other hand, the customer commented that these students did not ask for help or advices. The groups getting the highest rating from the customer did value getting feedback from different sources: the customer, user and the supervisor. This is in line with the results from Standish group [1], stating that user involvement is one of the most important success factors. The results from Procaccino et. al. [4] stating the importance of the customer and the developer having good relationship can be extended by our results, saying that both the customer and the developers have to find the relationship valuable.

The success factors that characterized the student project work in our study are very process oriented and very much in line with those stated by Verner, et. al. [6], where two of the most successful factors are: 'skilled project manager' and 'good schedule and estimates'. These student projects have very tight time schedule, only 18 weeks and a definite delivery date, there is no chance of getting some extra days, so it is not surprising that these factors lead to successful projects especially in these circumstances.

\section{Acknowledgements}

Our thanks to Anna Ingolfsdottir, Gudmundur Valsson, Jon Freyr Johannsson, Jonheidur Isleifsdottir and Jonina S. Larusdottir for their very valuable comments and inspiration on a draft of this paper. Also we would like to thank Yngvi Bjornsson for his proofreading and good comments on the final version.

\section{References}

1. Standish Group, Chaos Report, 1994, (cited December 2007), http://www.standishgroup.com/sample_research/chaos_1994_1.php

2. J. Johnson, My Life Is Failure: 100 Things You Should Know to be a Successful Project Leader. Standish Group International, West Yarmouth, MA, 2006.

3. K. L Linberg, Software Developer Perceptions about Software Project Failure: A Case Study, Journal of Systems and Software, 49(2-3), pp.177-192 (1999).

4. Procaccino, J. Drew, Verner, June M. and Lorenzet, Steven J. Defining and Contributing to Software Development Success, Communication of the ACM, 49(8). pp 79-83 (2006).

5. Dannelly, R. Stephen, DeNoia, Lynn, Student Opinions of Software Project Success, Proceedings of the 45th Annual Southeast Regional Conference, (Winston-Salem, North Carolina 2007), pp. 327-330. 
6. J. M. Verner, N. Cerpa, Australian Software Development: What Software Project Management Practices Lead to Success?, in: Australian Software Engineering Conference (ASWEC'05), (2005), pp. 70-77.

7. R. Berntsson-Svensson, A. Aurum, Successful Software Project and Products: An Empirical Investigation, Proceedings of the 2006 ACM/IEEE International Symposium on Empirical Software Engineering, 2006, pp. 144 - 153.

8. ISO/IEC TR 9126, Software engineering - Product quality, 19-12-2000. 